\title{
Analysis for Risk Factors and Effect of Vocal Hygiene Education in Patients of Vocal Polyp
}

\author{
Nayeon Choi' ${ }^{1}$, Dong Gyu Kim² (D), and GilJoon Lee ${ }^{\text {(D) }}$ \\ 'Department of Otorhinolaryngology-Head and Neck Surgery, Jeju National University School of Medicine, Jeju National University Hospital, \\ Jeju, Korea \\ ${ }^{2}$ Department of Otorhinolaryngology-Head and Neck Surgery, Kyungpook National University School of Medicine, Daegu, Korea
}

\section{성대 용종의 예후 인자와 음성 위생법 치료 효과 분석}

최나연 ${ }^{1}$, 김동규 ${ }^{2}$, 이길준 ${ }^{2}$

제주대학교 의과대학 이비인후-두경부외과학교실, ${ }^{1}$ 경북대학교 의과대학 이비인후-두경부외과학교실2

Background and Objectives Vocal polyp is one of the most common benign diseases of vocal fold caused by overuse of voice. Laryngeal microsurgery is the first treatment of choice for vocal polyp. However, surgery has many risks such as side effects of general anesthesia, injury of tooth and psychological burden. And we often experience reduction of vocal polyps without surgical procedure. The purpose of study is to evaluate the effect of non-surgical treatment such as vocal hygiene education and proton pump inhibitor (PPI) in patients with vocal polyp.

Materials and Method We performed retrospective study for seventy-three patients of vocal polyp who treated with non-surgical modalities such as vocal hygiene education and PPI over three months. Treatment outcomes and risk factors such as age, sex, polyp size, position, symptom duration, presence of laryngopharyngeal reflux (LPR) symptoms, smoking history, voice abuse history and vocal hygiene education were evaluated by comparison between polyp size improved group and non-improved group.

Results $5.5 \%$ of enrolled patients showed complete response and $23.3 \%$ showed partial response without surgery. Polyp size improved group significantly carried out more practice of vocal hygiene education treatment than the non-improved group $(p=0.040)$. And the presence of LPR symptoms [hazard ratio (HR) 3.368, confidence interval (CI) 1.055-10.754, $p=0.040$ ] and not performing of vocal hygiene education (HR 3.664, 95\% Cl 1.078-12.468, p=0.038).

Conclusion Vocal hygiene education can be a useful treatment option when making a decision to treat with vocal polyp.

Keywords Vocal polyp; Vocal hygiene; Proton pump inhibitor.

\section{서 론}

성대 용종(vocal polyp)은 양측 성문 간의 강한 물리적 접촉으로 인해 성대 고유층 (lamina propria) 내 액체 성분의 저류로 인해 발생한다. 목소리 과용, 남용에 의해 발생 할 수 있으며, 주로 목소리를 많이 사용해야 하는 교사, 상담원, 가수 등의 직업군에 호 발한다. 또한 잦은 기침이나 목 가다듬기, 고성 등에 의해서도 발생한다[1,2].
Received November 19, 2020

Revised December 5, 2020

Accepted December 17, 2020

\section{Corresponding Author}

GilJoon Lee, MD

Department of Otorhinolaryngology-

Head and Neck Surgery,

Chilgok Kyungpook National

University Hospital,

Kyungpook National University

School of Medicine,

807 Hoguk-ro, Buk-gu,

Daegu 41404, Korea

Tel +82-53-200-2166

Fax+82-53-200-2027

E-mail giljoon.lee@gmail.com

ORCID iDs

Nayeon Choi (iD)

https://orcid.org/0000-0002-0962-0594

Dong Gyu Kim (D)

https://orcid.org/0000-0002-4926-0239

GilJoon Lee (D)

https://orcid.org/0000-0002-3344-1879

This is an Open Access article distributed under the terms of the Creative Commons Attribution Non-Commercial License (https://creativecommons.org/ licenses/by-nc/4.0) which permits unrestricted non-commercial use, distribution, and reproduction in any medium, provided the original work is properly cited. 
성대 용종은 애성(hoarseness) 등 목소리 변성을 야기하며 이로 인해 일상 생활에 많은 불편감을 줄 수 있어 치료가 필 요하며 궁극적인 치료 방법은 수술적 제거이다[3-5]. 하지만 수술 시 전신마취에 대한 부담, 수술 과정 중 강직 후두경으 로 인한 치아 손상 가능성, 수술에 대한 환자의 심리적 부담 감, 재발 가능성 등의 고려 사항이 많아 쉽게 수술을 결정하 지 못하거나 수술을 거부하는 환자들이 있다.

성대 용종은 강하고 과도한 성문 접촉으로 발생하므로 이 를 억제 혹은 완화시킨다면 용종의 크기를 감소시킬 수 있을 것으로 기대할 수 있다. 실제로 임상에서 성대 용종에 대한 수 술적 치료 이외 음성 치료나 올바른 음성위생 교육, 양성자 펌 프 억제제(proton pump inhibitor, PPI) 사용, 금연 및 금주 교육, 충분한 수분 섭취 등의 비수술적 치료 방법을 활용하 고 있다[6,7].

이에 저자들은 성대 용종의 변화에 영향을 줄 수 있는 인 자들을 분석하고 비수술적 치료 방법으로 용종의 크기 변화 여부를 확인하기 위해 본 연구를 계획하였다.

\section{대상 및 방법}

2017년 9월 2020년 8월까지 이비인후과 외래에서 성대 용 종을 진단받은 환자 154 명 중 3 개월 이내 수술을 시행하였거 나 타 병원 전원 등 3 개월 이상 추적 관찰이 되지 않은 환자들 을 제외한 73명을 대상으로 하였다.

예후 인자로 연령, 성별, 성대 용종의 위치, 크기, 흡연 여부, 인후두 역류 증상의 유무, 발생 기간, 직업 등을 조사하였다. 성대 용종의 위치는 전교련부에서 성대돌기까지의 길이를 3 등 분 하여 전방부, 중반부, 후방부로 구분하였고, 크기는 성대의 전교련부(anterior commissure)에서 성대돌기(vocal process)까지의 길이를 6 등분하여 $1 / 6$ 이하는 소형, $1 / 3$ 이하는 중형, 그 이상은 대형으로 구분하였다. 인후두 역류 증상은 목의 이물감, 조이는 느낌, 만성 기침, 흥부 작열감 등의 여부 를 기준으로 조사하였다. 성대 용종의 발생 시기는 환자가 증 상을 호소한 순간부터 병원에서 후두 내시경을 통해 성대 용 종을 진단받은 순간까지를 기준으로 계산하였고, 직업은 교 사, 상담원, 자영업 등 하루 일과 중 목소리 사용 비중이 $50 \%$ 이상인 경우를 고위험군, 그렇지 않은 경우를 저위험군으로 분류하였다.

비수술적 치료 방법으로 음성위생법 교육 및 시행 여부, PPI 사용 유무를 조사하였다. 음성위생법은 밀폐된 공간에 서 1 2 $\mathrm{m}$ 정도 간격을 두고 상대방과 대화를 하는 정도의 목 소리 톤으로 목소리를 사용하고 노래나 고성 등 과도한 발성 및 속삭이는 발성을 자제하도록 교육하였다. 또한 경부의 근
육에 무리가 가는 운동이나 Valsalva법을 자제시켰으며, 하 루 $1.5 \mathrm{~L}$ 이상 충분한 수분 섭취를 하고 흡연이나 음주는 피 하도록 하였고 위산분비를 촉진하는 식단이나 자세를 피하게 하였다. 3 개월간 비수술적 방법을 시행한 후 성대 용종의 크

Table 1. Baseline characteristics and treatment outcomes of the patients with vocal polyp

\begin{tabular}{|c|c|}
\hline Clinical variable & Value \\
\hline \multicolumn{2}{|l|}{ Sex } \\
\hline Male & $44(60.3)$ \\
\hline Female & $29(39.7)$ \\
\hline Age (years) & $44.7 \pm 13.6$ \\
\hline \multicolumn{2}{|l|}{ Location } \\
\hline Anterior & $36(49.3)$ \\
\hline Middle & $34(46.6)$ \\
\hline Posterior & $3(4.1)$ \\
\hline \multicolumn{2}{|l|}{ Size } \\
\hline Small & $31(42.5)$ \\
\hline Medium & $37(50.7)$ \\
\hline Large & $5(6.8)$ \\
\hline \multicolumn{2}{|l|}{ Voice abuse } \\
\hline Low risk & $38(52.1)$ \\
\hline High risk & $35(47.9)$ \\
\hline \multicolumn{2}{|l|}{ Smoking } \\
\hline Yes & $34(46.6)$ \\
\hline No & $39(53.4)$ \\
\hline \multicolumn{2}{|l|}{ Laryngopharyngeal reflux } \\
\hline Yes & $40(54.8)$ \\
\hline No & $33(45.2)$ \\
\hline \multicolumn{2}{|l|}{ Proton pump inhibitor } \\
\hline Yes & $38(52.1)$ \\
\hline No & $35(47.9)$ \\
\hline \multicolumn{2}{|l|}{ Symptom duration (month) } \\
\hline$<1$ & $21(28.8)$ \\
\hline $1-3$ & $28(38.4)$ \\
\hline$>3$ & $24(32.9)$ \\
\hline \multicolumn{2}{|l|}{ Voice hygiene } \\
\hline Yes & $42(57.5)$ \\
\hline No & $31(42.5)$ \\
\hline \multicolumn{2}{|l|}{ Outcome } \\
\hline Disappeared & $4(5.5)$ \\
\hline Improved & $17(23.3)$ \\
\hline No change & $52(71.2)$ \\
\hline \multicolumn{2}{|l|}{ Outcome, symptom (Likert scale) } \\
\hline Very satisfied & $9(12.3)$ \\
\hline Satisfied & $16(21.9)$ \\
\hline No change & $25(34.2)$ \\
\hline Discomfort & $19(26.0)$ \\
\hline Very discomfort & $4(5.5)$ \\
\hline
\end{tabular}

Values are presented as $\mathrm{n}(\%)$ or mean \pm standard deviation 
기 변화 및 환자의 주관적 음성 만족도를 조사하였다.

통계분석은 SAS ver. 9.2(SAS Institute Inc., Cary, NC, USA) 프로그램을 이용하였고 피어슨 카이 제곱 검정, 로지스틱 회 귀분석 방법을 사용하였다. 다변량 로지스틱 회귀분석은 임 상적으로 중요한 변수라고 판단된 변수에 대해 시행하였고 단 변량 분석상 $\mathrm{p}$ value 0.2 이하의 값을 기준으로 변수를 선정 하였다. 분석값의 유의수준은 $\mathrm{p}<0.05$ 를 기준으로 하였다.

\section{결 과}

전체 대상 환자 73명의 성비는 남성 44명(60.3\%), 여성 29명 (39.7\%)로 남성이 많은 것으로 조사되었고 평균 연령은 44.7세 (19 74세)였다. 성대 용종의 발생 위치는 전방부 36명(49.3\%), 중반부 34명(46.6\%), 후방후 3명(4.1\%)의 양상이었으며 용종의 크기는 소형 31명(42.5\%), 중형 37명(50.7\%), 대형 5명(6.8\%)으 로 조사되어 주로 성문의 전방 $2 / 3$ 위치에 중, 소형의 용종이 다수를 차지하는 것을 알 수 있었다. 직업군을 포함해 음성 남용 여부를 조사하였고 저위험군 38명(52.1\%), 고위험군 35명 (47.9\%)으로 나타났으며 흡연 여부는 흡연자 34명(46.6\%), 비 흡연자 39 명 $(53.4 \%)$ 으로 비흡연자가 더 많은 것으로 조사되
었다. 인후두 역류 증상 여부는 40명(54.8\%)에서 동반하는 것 으로 나타났으며 증상 발생 시기부터 진단 후 치료를 시작한 시기까지의 기간은 1개월 미만이 21명(28.8\%) 1 3개월이 28 명(38.4\%), 3개월 초과가 24명(32.9\%)으로 조사되었다. 치료 로 음성위생법을 시행한 환자 수는 42명(57.5\%)으로 시행하지 않은 31 명(42.5\%)보다 $15 \%$ 많았다. PPI를 사용한 경우는 38 명(52.1\%)으로 나타났다. 3개월 간의 치료 후 성대 용종의 크 기 변화 및 환자의 주관적 만족도를 조사하였고 4명(5.5\%)에 서 완전 소실, 17 명(23.3\%)에서 호전되어 총 21명(28.8\%)에서 치료 효과가 있는 것으로 나타났고 52명(71.2\%)은 호전되지 않았다. 환자의 주관적 만족도상에서 9명(12.3\%)은 매우 만 족, 16명(21.9\%)은 만족한다고 답하여 총 25명(34.2\%)에서 치료 전에 비해 증상이 호전되었다고 응답하였고 이는 용종 의 크기가 호전된 비율과 차이는 보였다. 25명(34.2\%)에서 치 료 전과 큰 차이가 없다고 답하였고 19명(26.0\%)은 불만족, 4명 $(5.5 \%)$ 은 매우 불만족이라 응답해, $31.5 \%$ 에서 치료 전에 비해 증상은 오히려 불편해진 것으로 조사되었다(Table 1).

음성위생법과 PPI 사용을 통해 치료에 반응을 보인 용종 크기 호전군(21명, 28.8\%)과 비호전군(52명, $71.2 \%)$ 을 나누어 주요 인자로 생각되는 성별, 연령, 용종의 위치, 크기, 음성 남

Table 2. Comparison of clinical characteristics between the polyp size improved and non-improved group

\begin{tabular}{|c|c|c|c|}
\hline Clinical factor & Improved (n=21) & Remained $(\mathrm{n}=52)$ & p value \\
\hline Sex & & & 0.795 \\
\hline Male & $12(57.1)$ & $32(61.5)$ & \\
\hline Female & $9(42.9)$ & $20(38.5)$ & \\
\hline Age, years & $58.2 \pm 12.5$ & $58.9 \pm 12.4$ & 0.741 \\
\hline Location & & & 0.332 \\
\hline Anterior & $10(47.6)$ & $26(50.0)$ & \\
\hline Middle & $9(42.9)$ & $25(48.1)$ & \\
\hline Posterior & $2(9.5)$ & $1(1.9)$ & \\
\hline Size & & & 0.796 \\
\hline Small & $8(38.1)$ & $23(44.2)$ & \\
\hline Medium & $11(52.4)$ & $26(50.0)$ & \\
\hline Large & $2(9.5)$ & $3(5.8)$ & \\
\hline Voice abuse & & & 0.615 \\
\hline Low risk & $12(57.1)$ & $26(50.0)$ & \\
\hline High risk & $9(42.9)$ & $26(50.0)$ & \\
\hline Smoking & $13(61.9)$ & $21(40.4)$ & 0.123 \\
\hline Laryngopharyngeal reflux & $8(38.1)$ & $32(61.5)$ & 0.077 \\
\hline Proton pump inhibitor & $12(57.1)$ & $26(50.0)$ & 0.580 \\
\hline Symptom duration, month & & & 0.274 \\
\hline$<1$ & $7(33.3)$ & $14(26.9)$ & \\
\hline $1-3$ & $10(47.6)$ & $18(34.6)$ & \\
\hline$>3$ & $4(19.0)$ & $20(38.5)$ & \\
\hline Voice hygiene & $16(76.2)$ & $26(50.0)$ & 0.040 \\
\hline
\end{tabular}

Values are presented as $\mathrm{n}(\%)$ or mean \pm standard deviation 
용 정도, 흡연 유무, 인후두 역류 증상 유무, 발생 기간, 음성 위생법과 PPI 사용 여부에 따른 차이를 비교하였으며 호전군 에서 음성 위생법을 시행한 환자가 비호전군에 비해 많았으 며 이는 통계적으로 유의한 차이가 있었다 $(\mathrm{p}=0.040)($ Table 2).

치료에 반응하지 않았던 비호전군 52명을 대상으로 예후 인 자를 분석하기 위해 성별, 용종의 위치, 크기, 음성 남용 여부, 인후두 역류 증상 유무, 발생 기간, 음성위생법 및 PPI 사용 여부 등을 로지스틱 회귀분석을 통해 평가하였고 인후두 역 류 증상을 호소한 경우 증상이 없던 환자들에 비해 3.368배 위험이 증가하였고 이는 통계적으로 유의한 결과값으로 나타 났다 $(\mathrm{p}=0.040)$. 또한 음성위생법을 시행하지 않은 경우 시행한 환자군에 비해 3.665배 위험률이 증가하였고 이는 통계적으 로 유의한 것으로 조사되어 $(\mathrm{p}=0.038)$ 음성위생법 시행이 성 대 용종 크기 감소에 영향을 미친다는 것을 확인하였다. 하지 만 PPI 사용 효과는 없는 것으로 조사되었다(Table 3).

\section{고 찰}

성대 용종은 성문의 과도한 물리적 접촉으로 인한 점막 내 미세혈관의 파열의 결과로 성대 내부에 액체 저류 현상이 야 기되고 이로 인해 발생한다. 주로 남성에서 호발하고 음성을 과용, 남용하는 경우, 항응고제 복용 등 출혈성 경향을 가지 고 있는 환자, 인후두 역류 질환 등이 주 원인으로 알려져 있 다. 성대 용종에 대한 치료로 성대 휴식이나 PPI 사용 등 인 후두 역류에 대한 치료 등으로 시행하지만 실제 적극적으로 행하여지지는 못하고 대부분 수술적 치료를 시행하는 것이 일반적이다[8-10]. 수술적 치료는 후두미세수술을 통해 비교 적 단시간에 간단하게 제거할 수 있지만, 환자의 입장에서는 전신마취 위험성, 치아 손상 가능성 및 수술에 대한 심리적 부 담 등으로 수술적 치료를 쉽게 결정하지 못할 수 있다. 수술 적 치료를 결정하기 전 비수술적인 치료 방법을 적극적으로 시 행해보고 그로 인해 불필요한 수술을 줄일 수 있다면 의사,

Table 3. Clinical risk factors for non-improved group analyzed by univariate and multivariate logistic regression analysis

\begin{tabular}{|c|c|c|c|c|}
\hline & \multicolumn{2}{|c|}{ Univariate analysis } & \multicolumn{2}{|c|}{ Multivariate analysis } \\
\hline & HR $(95 \%$ CI $)$ & $p$ value & HR $(95 \%$ CI $)$ & $\overline{p \text { value }}$ \\
\hline \multicolumn{5}{|l|}{ Sex } \\
\hline Male & Ref & & & \\
\hline Female & $0.799(0.230-2.779)$ & 0.724 & & \\
\hline \multicolumn{5}{|l|}{ Location } \\
\hline Anterior & Ref & & & \\
\hline Middle & $0.911(0.253-3.276)$ & 0.887 & & \\
\hline Posterior & $0.212(0.011-3.923)$ & 0.298 & & \\
\hline \multicolumn{5}{|l|}{ Size } \\
\hline Small & Ref & & & \\
\hline Medium & $0.728(0.186-2.851)$ & 0.648 & & \\
\hline Large & $0.270(0.020-3.644)$ & 0.324 & & \\
\hline \multicolumn{5}{|l|}{ Voice abuse } \\
\hline Low risk & Ref & & & \\
\hline High risk & $1.981(0.546-7.188)$ & 0.299 & & \\
\hline \multicolumn{5}{|c|}{ Laryngopharyngeal reflux } \\
\hline No & Ref & & Ref & \\
\hline Yes & $3.137(0.798-12.334)$ & 0.102 & $3.368(1.055-10.754)$ & 0.040 \\
\hline \multicolumn{5}{|c|}{ Proton pump inhibitor } \\
\hline No & Ref & & & \\
\hline Yes & $0.632(0.156-2.556)$ & 0.520 & & \\
\hline \multicolumn{5}{|c|}{ Symptom duration, month } \\
\hline$<1$ & Ref & & & \\
\hline $1-3$ & $0.591(0.128-2.733)$ & 0.501 & & \\
\hline$>3$ & $2.167(0.377-12.439)$ & 0.386 & & \\
\hline \multicolumn{5}{|c|}{ Voice hygiene } \\
\hline Yes & Ref & & Ref & \\
\hline No & $4.197(1.112-15.841)$ & 0.034 & $3.665(1.078-12.468)$ & 0.038 \\
\hline
\end{tabular}

HR: hazard ratio, CI: confidence interval 
환자 모두에게 이득이 될 수 있을 것이다. 이미 음성 치료나 음성위생법, 인후두 역류 치료 등을 통한 비수술적 치료의 성대 용종에 대한 치료 효과를 보고한 연구들이 있다. Jeong 등[2]은 성대 용종 환자에서 3개월 이상 음성 치료를 시행하 고 38\%에서 용종이 소실됨을 보고하였고, Yun 등[7]은 88명 의 성대 용종 환자들을 대상으로 음성위생법 교육을 시행 하였고 약 $40 \%$ 의 호전율을 보고하였다. 이 외 다수 연구에 서 대체적으로 3 개월간의 음성 치료나 음성위생법 교육으 로 30 50\% 정도 용종의 크기가 감소하는 치료 효과를 보고 하였으며 크기가 작을수록, 여성일수록, 발생 기간이 짧을수 록 치료에 더 반응을 잘 하는 것으로 나타났다[3,4,9]. 본 연 구에서도 성별, 연령, 용종의 위치, 크기, 인후두 역류 증상 여 부, 발생 기간, 음성위생법 실천 유무, PPI 사용 유무 등 여러 변수에 대해 분석하였으며 전체 환자의 $28.8 \%$ 에서 수술적 치 료 없이 용종의 크기가 감소한 것으로 나타나 기존의 다른 연 구들과 비슷한 결과를 보였다. 또한 용종 크기 호전군과 비호 전군 간의 비교에서 연령, 성별, 위치, 크기, 음성 남용 유무, 흡 연, 인후두 역류 증상 유무 등의 변수들은 영향을 주지 않는 것으로 나타났지만 음성위생법은 호전군에서 실천 빈도가 높 았고 이는 통계적으로 유의한 차이를 보이는 결과로 나타나 적극적 음성위생법 실천이 용종 크기 감소에 도움이 된다는 것을 확인할 수 있었다. 이것은 성대 용종의 크기 감소에 음성 위생법이 도움이 될 가능성이 높으며 이를 검증하기 위한 추 가 연구로 음성위생법 실천 여부에 따른 성대 용종의 크기 호 전에 대한 무작위 대조군 연구 등이 필요할 것으로 사료된다. 예후 인자로 생각되는 여러 요인들의 분석에서 인후두 역류 증상, 음성위생법 실천의 유무를 제외한 성별, 용종의 크기, 용종의 발생 기간, 음성 남용 정도, 흡연, PPI 사용 유무 등은 통계적으로 의미 있는 결과가 나오지 않았다. 전체 대상 환자 수가 적은 점, 음성 남용 정도, 흡연 유무, 발생 기간 등은 환 자의 진술에 의존해 조사가 이루어진 점, 그리고 각 변수 간 상호작용, 예컨대 용종의 크기가 작은 여성 환자는 예후가 좋 을 것으로 예측하지만 이 환자가 흡연을 하는 음성 사용도가 높은 직업군에 종사하는 경우에 대한 분석이 부족한 점 등이 그 원인으로 지적될 수 있을 것이다.

본 연구를 통해 3 개월 이상의 음성위생법의 교육 및 실천 이 성대 용종의 크기 감소에 도움이 된다는 것을 확인할 수 있었다. 하지만 예후 인자 분석에는 부족한 점이 있었던 바 대 상 환자군을 확대하고 예후 인자에 대한 정밀한 분석이 더해 진다면 성대 용종의 예후를 예측하고 정확한 치료 방침 세우 는 데 도움을 줄 수 있을 것으로 사료된다.

\section{결 론}

성대 용종의 치료 방침을 정함에 있어 3개월 이상 적극적인 음성위생법을 통해 약 $30 \%$ 정도 성대 용종의 크기 감소 효 과를 기대할 수 있다. 또한 인후두 역류 증상이 있는 경우나 음성위생법을 소홀히 하였을 때 성대 용종의 비수술적 치료 효과는 감소하는 것을 확인하였다. 성대 용종의 치료 방침을 결정함에 있어 수술적 치료를 결정하기 전 초치료 과정으로 음성 위생법 통한 비수술적 치료를 고려해 볼 수 있다.

중심 단어: 성대 용종, 음성 위생, 양성자 펌프 억제제.

Acknowledgments

None.

Conflicts of Interest

The authors have no financial conflicts of interest.

Authors' Contribution

Conceptualization: GilJoon Lee. Data curation: all authors. Formal analysis: Nayeon Choi, GilJoon Lee. Investigation: all authors. Methodology: GilJoon Lee. Validation: Nayeon Choi, GilJoon Lee. Visualization: Nayeon Choi, GilJoon Lee. Writing-original draft: Nayeon Choi, GilJoon Lee. Writing-review \& editing: Nayeon Choi, GilJoon Lee. Approval of final manuscript: all authors.

\section{REFERENCES}

1. Srirompotong S, Saeseow P, Vatanasapt P. Small vocal cord polyps: completely resolved with conservative treatment. Southeast Asian J Trop Med Public Health 2004;35(1):169-71.

2. Jeong WJ, Lee SJ, Lee WY, Chang H, Ahn SH. Conservative management for vocal fold polyps. JAMA Otolaryngol Head Neck Surg 2014; 140(5):448-52.

3. Cho KJ, Nam IC, Hwang YS, Shim MR, Park JO, Cho JH, et al. Analysis of factors influencing voice quality and therapeutic approaches in vocal polyp patients. Eur Arch Otorhinolaryngol 2011;268(9):1321-7.

4. Cohen SM, Garrett CG. Utility of voice therapy in the management of vocal fold polyps and cysts. Otolaryngol Head Neck Surg 2007;136(5): 742-6.

5. Johns MM. Update on the etiology, diagnosis, and treatment of vocal fold nodules, polyps, and cysts. Curr Opin Otolaryngol Head Neck Surg 2003;11(6):456-61.

6. Verdolini-Marston K, Sandage M, Titze IR. Effect of hydration treatments on laryngeal nodules and polyps and related voice measures. J Voice 1994;8(1):30-47.

7. Yun YS, Kim SW, Baek CH, Jeong HS, Son YI. Effect of vocal hygiene education in the patients with vocal polyp. Korean J Otorhinolaryngol-Head Neck Surg 2006;49(7): 728-32.

8. Ju YH, Jung KY, Kwon SY, Woo JS, Cho JG, Park MW, et al. Effect of voice therapy after phonomicrosurgery for vocal polyps: a prospective, historically controlled, clinical study. J Laryngol Otol 2013;127(11): 1134-8.

9. Lee SW. Treatment outcomes and prognosis of benign vocal fold lesions. J Korean Soc Laryngol Phoniatr Logop 2015;26(2):101-3.

10. Garrett CG, Ossoff RH. Phonomicrosurgery II: surgical techniques. Otolaryngol Clin North Am 2000;33(5):1063-70. 